\title{
Does Online Education Need a Special Pedagogy?
}

\author{
Peter Serdyukov \\ Teacher Education Department, National University, La Jolla, California, USA
}

\begin{abstract}
The extensive integration of information technologies in teaching and learning in the $21^{\text {st }}$ century has initiated a dramatic change of educational paradigm. To a large extent this change was caused by the online education. A rapid growth of online university programs raises a number of new pedagogical, psychological and social issues. Online learning creates a learning environment that, compared to traditional, classroom-based education, is less personal, more independent, often fragmented, rarely systemic, distributed in space and time, and dependent on the learner rather than on the teacher. Many problems with online education (high attrition rate, orientation at highly skilled and highly motivated people, among other issues (The Trouble with Online College, 2013), indicate that one of its major challenges is not the technology itself or its classroom applications, but the lack of sound, research-based theoretical framework as the foundation of quality online learning. A comprehensive and effective educational theory is thus crucial for the quality education. This article makes an argument for such a theory and offers a model of online pedagogy for higher education with a focus on instruction and instructor, student autonomy, socialization through networking and collaboration in the online learning environment.
\end{abstract}

Keywords: online education, pedagogy, web-based learning, teaching and learning, student-centered approach, convenience, socialization, networking, communication, collaboration

\section{Introduction}

To increase online university educational effectiveness and to understand how students learn and how teachers teach best in an online environment necessitates a comprehensive theory based on sound, continuous pedagogic research. Classic pedagogy has served numerous generations of brick-and-mortar university professors and students well, however it cannot satisfy online teachers and learners, as "rapid changes in knowledge and technology are driving the need for new approaches to dissemination and integration of new information into workplaces and work practices, and new learning paths for adults" (Haythornthwate \& Andrews, 2011, 1).

Many great minds contributed to the development of pedagogy as a science, among them Johann Heinrich Pestalozzi, John Amos Comenius, John Dewey, Lev Vygotsky, Jean Piaget, Jerome Bruner, and many others. According to Jerome Bruner (1999), pedagogy is a science that makes educators aware of different teaching and learning standards and strategies which guide what, to whom, how and when to teach. So, when teaching, instructors select the content and implement the strategies that best fit a particular group of students in a classroom situation based on this science together with their own professional experiences. Students also need well-formulated guidelines to learn efficiently. Online education, however, does not yet have its own pedagogy.

The need for an innovative pedagogy is conditioned by a number of factors.

$21^{\text {st }}$ century economy needs creative, openminded, critically thinking workers who do not just acquire certain knowledge and skills in a university, but develop an ability to construct new knowledge, solve unique problems, and develop original ideas.

Online education is different from conventional university education in structure, format, learning environment and process, instructional tools, content presentation, student objectives, attitudes, learning skills, interaction, communication, collaboration, as well as in student relationships within the group, with the instructor, and the real world outside the university 
Online students are a new class of learners: they have grown up in the technology-rich environment and are effective users of modern gadgets; current student generation has diverse life goals and less certain job future, is more independent, mobile, demanding, and less inclined to accept the authority of their teachers. In addition they commonly have a shorter attention span, decreased capacity for learning, weaker reading and writing skills, and socialize in nontraditional ways via the Internet and social networking.

College instructors are mostly of middle or older age, burdened with the traditional teaching theory and experiences, and not very friendly with new technologies preferring to stay with those they have already mastered.

So, what do students need to succeed in online learning, and how can their teachers help them? Let's consider various aspects of online education.

\section{What Interferes With Quality Online Education?}

With the launch of online education about three decades ago, few educators if any thought of a special pedagogy for this revolutionary approach. The instructional problems they faced in online classes were, consequently, resolved through straightforward integration of technology into the existing teaching practice. They "have adopted new technologies largely through trial-and-error methods and by adapting traditional didactic practices to online environments" (Harasim, 2012, 3). The role of technology in teaching and learning in the beginning was clearly assistive, or supportive, hence the terms Computer-Assisted or Computer-Aided Learning (CAL), and Computer-Assisted Instruction (CAI) (Microsoft Encarta, 2001). Soon, however, educators started designing and teaching their courses with significant Information and Communication Technology (ICT) enhancement; thus the terms Computer-Based Learning (CBL) and Web-Based Learning (WBL) appeared (Web-Based Learning, 2013). And still, there was little serious theoretical work underway, as demonstrated, for instance, in scholarly presentations at educational technology conferences in the 1990s and 2000s which were focused predominantly on the emerging technologies and their applications, rather than on pedagogic or methodological issues.

Thus, from the beginning to the present time technology-based education has been led not by a comprehensive theory, but by the technology, which is basically just an instructional tool, and by its largely unsubstantiated applications in teaching. Consequently, instead of designing new pedagogy or, at least, transforming the conventional pedagogy to integrate the educational capabilities of new technologies, a common trend in higher education institutions has been to merely adapt technology to traditional teaching ways. Professional development of instructors in new technology-based education has also been concentrated on operating continuously evolving technological tools without providing valuable theoretical underpinnings or reliable research. This often resulted in ineffective classroom applications and/or superficial renovation of traditional educational practices that did not produce significant gains in the learning.

As online education has become recognized by both the society and employers, and the enrollments significantly increased in the first decade of the $21^{\text {st }}$ century, there appeared numerous programmatic and methodological questions about online teaching and learning and the quality of educational outcomes (Miller, et al., 2014). This prompted the demand for a specific pedagogy which could explain how to teach and learn in the online environment. Yet, to this day we see that technology drives the learning, while online pedagogy is lagging behind. Online education is often classified by the technologies used, not pedagogy (Anderson \& Dron, 2011). As Mark Nickols states, in online education "an overall educational framework is still missing" $(2011,322)$. He writes further on, "the term 'education' is generally missing from e-learning conversation". True, the focus of online educators is on the generic term 'learning' that narrows the concept of education which embraces various deeper aspects of the formative development.

More disquieting than even the lack of pedagogical foundation is the sincere belief of many educators that technology will "fix" all the problems they encounter in the classrooms, either 
live, or virtual. Consequently, few university instructors nowadays perceive the need for pedagogic mastery in online teaching in addition to the content-area expertise as they reason technology will solve all difficulties anyway. This belief is called 'technocentrism' (Pappert, 1990), which, according to Nickols (2011), is very common in higher education and e-learning discussions. Practicing educators, unfortunately, often forget that the computer is only an extension of human abilities not their replacement or substitute. One of my students wrote in a recent class, "Students learn from their teachers, not from electronic gadgets". True, interaction between students and their teachers offers worthy examples and enlightening experiences for students and gratifying moments for teachers. The overestimation of the power of technology, regrettably, leads to the deterioration of the "human element" (Serdiukov, 2001) in online teaching and learning and further underestimation of the need for sound pedagogy and quality instructor preparation.

There is another concern over online education. Neil Postman cautioned against 'surrendering education to technology' (Postman, 1993), which may have far-reaching social and cultural consequences. According to Sousa (2014), the widespread use of technology is having both positive and negative effects on our students' attention and memory systems. A strong warning about the negative effects of the Web comes from Maurer, Mehmood, \& KoricaPehserl (2013), who caution that modern media, particularly networked computers, are endangering our capacity to think, to remember clearly, and to read and write with concentration; they also endanger creativity. As online education is definitely going to grow, we need to make it really effective, and at the same time try to minimize its negative effects, which reaffirms the need for a comprehensive theory.

To emphasize the urgency of developing pedagogy for online education, Linda Harasim in her "Learning theory and online technologies" (2012) writes, "the field lacks a theoretical framework to guide educational design, pedagogies and use of online technologies" (p. 2). Despite almost thirty years of online education and numerous publications on its various aspects, there have been only a few attempts to create a solid theory of online education (Siemens,
2005, Nichols, 2011; Anderson \& Dron, 2011; Haythornthwaite \& Andrews, 2011; Harasim, 2012; Simonson, et al., 2012). What is the reason of that? There are, in our opinion, three plausible answers to this question:

1. With the rising demand for online programs and severe competition for enrollment, universities are embracing the new educational format and technologies with such enthusiasm that they have no resources left to sustain fundamental pedagogic research and provide adequate online instructor preparation.

2. College educators who became online instructors, under the stress of continuously mastering ever changing and increasingly more complex technological tools, find no time or capacity to do research, theorize on online practices, and put together a comprehensive online pedagogy.

3. The majority of the online educators, besides, are either teaching practitioners or experts in the content area without sufficient educational expertise. Few of them are even interested in pedagogic research.

What is needed to develop online pedagogy is a team of educational theoreticians; unfortunately, those belong to the traditional pedagogy. Emerging online pedagogy must have its own theoreticians and should move from the description of minute applications and unconnected technicalities to the all-embracing, consistent theory of contemporary web-based education.

E-learning, incidentally, is only a slice of online education, which itself is a part of general educational theory and practice, so it cannot brand the whole process of college education. Online educators have to overcome a narrow, pragmatic view of the new field. There are also many other inconsistences in the current approach to online education. For instance, online discourse not only uses the terms 'learning' instead of 'education', but also 'delivery' instead of 'instruction', 'facilitation' instead of 'teaching'; students do not read but 'google', 'browse', and 'skim' instructional materials; they do not study but press the keys, click the icons, peruse available information and select answers in lieu of solving problems; post or text rather than communicate and relate. Students seldom visit libraries and read professional literature. Many are tempted 
to try to get a fast grade and degree and leave online classes behind as soon as they can (they, so to say, "fly" above the course without landing (Serdyukov \& Hill, 2008); do they have time to stop and think deep in the online learning race? As a result, some of them may not have a chance to construct deep, holistic knowledge, learn to socialize and collaborate, or grow as professionals. Commercialism (Higher Education: Open for Business, 2007) is robbing education of its original and everlasting noble intent to elevate people.

\section{Convenience Factor}

Online education, besides the lack of its own pedagogy, is also affected by the convenience factor (Bocchi, Eastman, \& Swift, 2004; Serdyukov \& Serdyukova, 2006, Mupinga, Nora, \& Yaw, 2006), which is the primary reason of general fascination with it. Online education is like Starbucks which is not so much about coffee; it is about its patron's enjoyment with a wide choice of favorite coffee-based drinks (espresso, latte, mocha, macchiato, Frappuccino; with vanilla, caramel, pumpkin and other flavors) in a comfortable, familiar environment. Online education also provides a similar environment and the desirable product (various courses) integrated into the same Learning Management System (LMS) with numerous support mechanisms (instructor, helpdesk, concierge, etc.), with makes it stress-free, convenient and ubiquitous. But is an online class about true education? Probably it is not, it is about us, our ego (degrees and diplomas), careers, culture, habits, and, of course, enjoyment in a comfort zone.

However appealing for students, convenience can be detrimental to academic rigor and may affect students' attitudes towards learning. Experts notice, for instance, handwriting is being sacrificed for the sake of technology's convenience (Casey, 2013), while research proves handwriting enhances understanding and retention (Sousa, 2014). Have not we reduced visiting with friends and colleagues and engaging in live communication with them because of the internet, smartphones, Skype, emails, social networking and texting?
Convenience in education is related to the principle of the least effort (Zipf, 1949), which brings humans to employ economies of effort in many processes of mental tasks, including learning. Research (Reichle, Carpenter, Just, 2000) demonstrates human brains seek to minimize the mental workload by choosing the strategy that makes less work for the brain. According to Liu \&Yang (2004), students show strong preference for easy and fast information retrieval, therefore they are looking for convenient ways to accomplish their learning with the least effort, take shortcuts, and thus miss many educational benefits for the sake of a quick grade or faster completion of the university program.

The pursuit of convenience sometimes leads to discoveries; more often than not, though, it may bring about lack of responsibility, slack performance and intellectual deprivation. Online learning based on the convenience model develops not only innovative methods of learning, but also impairs students' cognitive abilities and dispositions for learning (Spitzer, 2012). Students in online classes not only avoid attendance of the college classrooms that are half-empty today, but also try to evade participation in the synchronous online activities intended to bridge the separation between college, instructors and online students, such as chats and live telecommunication sessions, simply because they require more engagement, time and effort. At the same time, they eagerly indulge in the outof-class social networking via iphones. In addition, the instructor's facilitation of learning makes cognitive tasks easier, student's responsibility for his or her own learning lower, and sense of entitlement stronger, so students have learned to expect immediate, continuous, allaround support, reduced rigor and high grades in online classes, especially offered by private institutions.

Moreover, online learning presents students with numerous opportunities for reducing their mental efforts, hence wide-spread plagiarism and focus on swift, tangible results in the form of the grades, certificates and degrees. Mobile learning (m-learning), a recent addition, takes online education further along this road, and already obliges instructor to be on call $24 / 7$, as it "provides greater flexibility for students to be examined or interact at any time and in any place" (Sampson, et al., 2013, 72), which definitely enhances the convenience of learning 
while increasing the demand on the instructor's time; but does it help better learning?

\section{Learner-Centered Approach}

The factor of convenience in online learning is interrelated with the learner-centered approach developed by John Dewey, Jean Piaget, Lev Vygotsky, and Carl Rogers, which is adopted by online education. The student is now the central figure of the educational process, not the instructor, who is no longer expected to perform the leadership function. The instructor now plays a supportive role called facilitation, but does it add to students' sense of responsibility, self-efficacy, and steers them to better performance? We believe this situation creates the Paradox of the teacher and the student in contemporary education, where the teacher and learner assume opposing roles, which runs counter to the original intent of education.

The online student is expected to be an independent, autonomous, self-efficient learner. Actually, online education is intended for highly skilled and highly motivated people, but inappropriate for struggling students who make up a significant portion of college enrollment (The Trouble with Online College, 2013). Online teaching, i.e., facilitation, serves not so much to educate as to support the student in his or her independent learning. Student-centeredness as a pedagogic principle, however attractive in its democratic intent, nonetheless is deceptive: only very few able, highly motivated, dedicated, self-directed learners know what they want to learn and how to study, and are capable of assuming both the rights and responsibilities of independent learning. It is publicly known that the majority of US school graduates failed by general education (according to some estimates, up to $75 \%$ ) are not ready for college (College preparedness, 2012). This indicates, among other things, to the fact that they are incapable of independent learning. Our own recent research of autonomous learning perceptions among online US university students taking graduate teacher education programs (Serdyukova \& Serdyukov, 2013) demonstrates that the majority of surveyed students (working adults) $-62.0 \%$ prefer to take university-organized, teacher-led classes rather than learn independently, while only $34.9 \%$ stated they could do it.
This research shows that these students are generally not enthusiastic about learning on their own. Many students rely on a straightforward course structure and unambiguous organization of the class, direct leadership, strong support and even pressure from the instructor. They are willing to trade the benefits of autonomous learning for the security of instructor-facilitated class, thus demonstrating their dependence on outside factors for their success rather than on their own skills and abilities. It appears that in the online learning environment, which counts on students' self-efficacy due to its nature, some students feel lost and unsure of their capability to cope with course demands. The need in externally imposed structure, organization and obligation might be explained by students' lack of confidence in their abilities to accomplish their learning independently. This dismal self-reliance feature comes, as the study demonstrated, from poor learning habits and time management skills, lack of diligence, persistence and effort, as well as insufficient learning skills (reading, writing, critical thinking, and research), low motivation, deficient selfevaluation and other factors. All this points to their poor school and even previous college preparation as they all had university degrees. Remarkably, within the same university classes $76.9 \%$ of the surveyed students stated they preferred to study independently, while only $18.5 \%$ did not mind collaborating with their peers and even fewer, $4.6 \%$, enjoyed both options. This preference of independent learning within the online classroom can be explained, in our opinion, by the virtuality of online learning and prevalent societal culture.

Online education by definition is an independent, autonomous learning (Moore \& Kearsley, 2011). Learner-centered approach, however, can work only for the self-efficient, mature learners, who, regrettably, are few in our classrooms. Unprepared, unskilled, and dependent students in learner-centered online environment are at risk of failure, if not in the grades then in the basic competencies. It looks like contemporary students need to have a better basic preparation before they enroll in college classes, stronger work ethics and more personal responsibility for their own learning. They also need qualified instructors. 


\section{Online Instructor's Challenges}

The success of online education depends not only on the unlimited resources of the internet and effective technology to deliver the content, but also on how students learn in the online environment and how instructors support their learning (Herrington, Bunker, 2002). In an online university class instructors are no longer required to write and deliver their own lectures, which traditionally was a major demonstration of high professorial competence. They ceased to be the leaders in the learning process and instead started performing mostly service functions. Everything in an online class, including the content, has been developed by the course designers and embedded into the course. The online instructor's main function nowadays is to facilitate students' learning, i.e. keep the course procedure alive - the instructor stays on the side of the process and observes students' independent struggling with the content and assignments.

A competent, caring and responsible instructor will intervene and help; a poor instructor will either ignore students' struggles or suggest that the student tackles the problem on her own, using clearly stated tasks, assignments course materials and internet resources. There is often little instructor's personal involvement with online students, minimal cognitive, educational cultural and emotional impact, and practically no role modeling in the learner-centered online classes (Hill, Serdyukov, 2010). Interactions with students are limited in format, time and engagement, and feedback is commonly delayed while often incomplete and non-specific. When students fail, nevertheless, it is usually not the online environment that is at fault but incompetent instructors, as well as students' own unpreparedness, lack of motivation, perseverance, learning skills, and poor work ethics. The instructors' methodological incompetence, conversely, is typically not their culpability: they have never been prepared to teach online, did not have a chance to learn from good role models themselves, nor ever mastered pedagogy. Equally, it is not the technology we should blame for the students' failures, but the users' inability to apply it effectively to pedagogic tasks, either the instructors', or the learners', or both.
Online courses contain the content in a variety of modalities, such as text, audio, visuals, videos, and multimedia, which are integrated in the course shell. Students have to interact with this content and construct their own knowledge. The content, however, is only a part of the learning. The "how" in learning, which is defined by the pedagogy and instructional methodology, is no less important for success than the "what" which is the content. Success in learning, as stated by Association of Learning Technologies (2010) is "process led rather than content or technology led". Thus, critical for the success of learning is the instructor as the central figure in the learning process, her qualifications and dispositions that are defined by the pedagogy.

Three types of online instructors can be identified based on their involvement in the class:

1. Leaders: Those who are on top of everything, and lead student learning (excessively active).

2. Facilitators: Those who are there only to respond to students' questions and provide minimal support when requested (reactive/ passive).

3. Mediators: Those who are on a par with students, artfully engaging and interacting, but without direct management (reasonably active).

In an online class, the third type is definitely preferable to the other two.

In every type of education, incidentally, there is one more critical teacher function, the mentorship, which provides crucial differentiation and individualization in learning. While online education typically stresses the facilitator role, the mentor's role is not even considered, while it remains vital and can be easily effectuated if the instructor chooses to engage in one-to-one interaction with a student focusing on her individual needs. Instructor roles, including the one of the mentor, should also be a part of e-pedagogy.

The cadres of online instructors, while playing around the prepackaged embedded course content, often do not use pedagogic skills or simply lack them because they have never learnt online pedagogy. Others, especially those who come to online classes from traditional classroombased institutions are having a hard time transferring their teaching skills to the new, virtual 
classrooms. Those specialists who come to teaching online without previous classroom experiences, e.g., from business, industry, civic administration, or other fields are not familiar with pedagogic principles of education at all and are struggling with challenges of online teaching. Quite a few experienced online instructors, following the principle of the least effort mentioned above and enjoying the factor of convenience as much as students, have developed instructional techniques suitable for the Ford's conveyor. When they teach the same course continuously, they create a database of instructional materials, visuals, assignments, projects, tests, and even discussion posts or critical comments on students' work, which they peruse from class to class without updating, only adjusting them to the class circumstances or students' products. This is common among many instructors, but more so among the growing category of part-time, adjunct instructors, who have a very superficial connection to the departments and less accountability for the learning outcomes.

The philosophy of teaching has changed. Diminished expectations for the instructors' academic status due to their subservient role lead to their lower academic expertise, lesser influence, smaller impact on students, minimal responsibility and, consequently, reduced academic rigor of the teaching which results in poorer learning outcomes. We have created a dubious situation: one the one hand, we instill in teachers the notion they are leaders, on the other, we put them in the secondary, limited-authority, vulnerable position in school and university, deprive them of their leader's rights, and yet ultimately blame them for students' failures!

It is indispensable that online instructors are specially trained by universities. Before allowing new instructors to teach online, they must be thoroughly prepared in online pedagogy and instructional methodology. Universities do provide some professional development, however it is commonly haphazard and limited - there is no solid and systemic pedagogy, and no accepted rigorous protocol for online instructor assessment, follow up, support and guidance, as well as preparation; objective feedback is often missing. Administrative and peer visitations which contribute to an instructor's professional growth are commonly rare and seldom critical.
Such a lax culture hinders instructor's professional growth and negatively affects students' achievements. E-pedagogy needs to address these issues.

\section{Communication, Socialization and Collaboration in the Online Environment}

Learning, to be successful, cannot be solely an internal, individual activity. It takes place through interaction with the environment, particularly with people and information. Online learning, though highly individualized, in order to be successful, needs to take place in learning communities, even more than in onsite classrooms. While we should stimulate online learner autonomy, complete individualization and independence of the learning, however, may affect learning outcomes that thrive on open communication and strong relationships, especially in view of the social constructivist theory which advocates collaboration and cooperation.

Communication is key to effective learning as it plays a crucial role by helping develop cognitive skills, construct and transfer knowledge, socialize and establish a learning community. It also enables the sharing of information, thoughts and ideas which contribute to learning. Information transforms into knowledge through communication. "Knowledge is socially constructed, and best supported through collaborations designed so that participants share knowledge and tackle projects that incorporate features of adult teamwork, real-world content, and use of varied information sources"(Scardamalia \& Bereiter 2002). As knowledge is being constructed in communication, so the sense of learning is being created via communication, like the "meaning is a phenomenon of thought only in so far as thought is embodied in speech" (Vygotsky 1962, 153). Discourse, from a constructivist perspective, is a central mechanism for learning (Palincsar, 1998). Communication actually creates opportunities for the learning to take place. Besides, it also helps to instill and maintain enthusiasm in learners, increase motivation, and build positive relationships among learners and with the instructor. So, direct personal communication among students and between students and their teacher is an indispensable component of any learning. 
In an online environment where students can no longer personally experience and acquire knowledge, they need to construct their own personal knowledge by communicating with other students and instructors and establishing whatever relationships they can that help communication, collaboration and cooperation. Learner's ability to construct internal knowledge depends on his or her skills to locate the needed knowledge, select, evaluate, and apply it, which happens in the interactions not only with the information and computers, but also with people. "We derive our competence from forming connections" (Siemens, 2003, 3). To facilitate effective and continuous learning, instructors have to maintain and nurture connections among all participants, thus creating a community of practice (Lave \& Wenger, 1991), capable of sustaining the challenges of learning.

In online classes there is in-class and out-ofclass communication, both of which can be done in various ways - via email, telephone and networking.

As shown in Table 1, communication can be either text-based or voice/video-based; the former is commonly done via threaded discussions and texting, and the latter via live sessions (videoconferencing) and telephone, or played back to reuse. Threaded discussions, emails and recordings are asynchronous, and networking via texting, as well as all live interactive sessions, are synchronous. These types of communication are used in online classes with a varying effectiveness.

\begin{tabular}{|c|c|c|}
\hline $\begin{array}{c}\text { Temporal } \\
\text { organization / Form }\end{array}$ & Text-based & $\begin{array}{c}\text { Voice / } \\
\text { video-based }\end{array}$ \\
\hline \hline Asynchronous & $\begin{array}{c}\text { Threaded discussion, } \\
\text { email }\end{array}$ & $\begin{array}{c}\text { Voice/video } \\
\text { recording }\end{array}$ \\
\hline Synchronous & Texting & $\begin{array}{c}\text { Live sessions, } \\
\text { telephone }\end{array}$ \\
\hline
\end{tabular}

Table 1. Interactions in online environment.

All online interactions can serve two major functions: cognitive and social. Both cognitive and social interactions contribute to knowledge construction which has the most pronounced effect in threaded discussions. Actually, these discussion serve as one of the most effective mechanism of knowledge construction, where students post information, share their knowledge, comment on other students' and instructor's posts, express their opinions, add new information, and argue (Knowlton, 2001; HmeloSilver, 2003), which contributes to deeper learning. Moreover, they are convenient due to their asynchronous character.

While cognitive interaction is necessary for building knowledge and solving problems stemming from the course content, social interaction is also crucial for supporting the learning via its capacity to enhance the development of student behaviors, attitudes and relationships. Three of the more pronounced benefits of the social interaction for learners included improved learning strategies, greater perseverance, and reduced need for help from the instructor (Lou, Abrami, \& d'Apollonia, 2001), thus augmenting their self-efficacy. These outcomes are especially important in online education because of the inherent difficulties with learning without the structure and motivational elements of an inperson classroom setting (Moore, 2001). Social interaction, therefore, provides critical support for online learners who are separated from the school, instructor and peers.

As online learning is, by definition, an independent learning, learning by reading the textbook and/or online materials, writing essays, solving problems, and posting answers to the course questions or discussion prompts cannot ensure quality of the learning outcomes. Effective learning requires that the student interacts with the peers and the instructor. Yet, this is the weakest spot in online learning. As Eric Clark wrote, communication is the Achilles Heel of online learning (Clark, 2013). Why? First, it is difficult to communicate effectively via technology with the people you do not know. Second, communication takes precious time, and when students are busy and do not appreciate the value of communication in learning, they prefer to shy away from it. Threaded discussions are a text document with clear requirements, therefore students are obliged to participate in them. Yet to engage students in a genuine communication is extremely difficult. For instance, in live sessions, even when they are graded, attendance in our classes commonly reaches only about $50 \%$ of the roster despite all instructor's efforts; the rest of the students have valid reasons to stay away and instead, if there 
is an alternate option, prefer to submit a written assignment. When live sessions are optional, attendance does not usually exceed $30 \%$ of the class. The reason is evidently the synchronicity of such session which makes it inconvenient for the working adults.

What part of the online course does communication occupy? We conducted a survey in an attempt to determine the time students spend on various activities in an online class. As we found out (Serdyukov \& Serdyukova 2009), communication in an online class takes only a small portion of students' time: per course students spend in threaded discussion 6.85 hour, in direct communications with peers (outside the discussions, via emails) 3.64 hour, with the instructor 1.55 hour, total 12.04 hours out of 62.95 hours invested in the class, or $19.05 \%$. The rest goes to doing assignments, writing a final paper, reading, testing, and some technical issues with the course - mostly independent work. Thus, the active, communicative part of the learning takes less than $1 / 5$ of the class time. Synchronous live sessions using videoconferencing, such as ClassLivePro, take, when integrated in the course, only 4 hours per course, which makes up to $6.35 \%$ of the class time that adds to the overall communication time which still remains low - only $25 \%$ of the class time. It is problematic to develop collaboration if students are reluctant to communicate with each other.

Educators face various challenges in organizing student communication and collaboration in the online class:

- How to engage students in communication and collaboration?

- Will the course structure, integrated communication tools and assignments induce them to communicate and collaborate? Or it depends solely on the instructor?

- Which is the primary driver of communication and collaboration in the class: the cognitive or social networking?

- Is it possible to develop personal relationships within an online class?

There are many other questions awaiting the answers.

Collaboration through networking as team work is needed either to build knowledge more effec- tively, or solve complex learning problems, or develop projects of scale. There are three levels of collaboration via networking in an online class:

- Pair-share - individual questions, private conversations (students)

- Team (small group) - discussion, problem solving, project development, brainstorming (students, and when necessary, the instructor)

- Whole class - general discussion (instructor and class)

There are also individual in-class communications between the instructor and students. In addition, there is student networking outside the class, whether one-on-one with the peers or in a group.

Collaboration is commonly a small team work shared between 3-5 students. The team has a task or a project with a focus on a common goal. Each team member has a role, personal objective, task, and information, all of which contributes to the achievement of a common goal. The purpose of team activity is to achieve the preset goal by combining members' efforts via communication and collaboration.

Online learning puts an additional responsibility on the instructor to foster a communication-rich, collaborative learning environment. An understanding of social dynamics, including instructor immediacy and classroom community, can assist online instructors as they seek to develop the communal scaffolding necessary to support an effective learning environment (Bake, Woods, 2005).

Based on his own experiences, the author suggests seven stages of the collaborative activity which can be organized by the instructor:

\section{Setting a goal (comes from the instructor)}

2. Creating a plan of actions, identifying objectives, outcomes, structure of the activity, organization, roles and materials (whole class and then collaborative work by teams with the possible instructor's involvement if needed)

3. Independent work, search of ideas and solutions, information processing (students independently) 
4. Communicating and collaborating to generate solution and new knowledge (team)

5. Putting together and shaping up the product of activity, e.g., project (team)

6. Presentation, discussion, critique (group)

7. Reflection (independently, team and group)

Some of these steps can be done within the class using course communication tools in LMS $(1,2$, $6,7)$, others can be done through students' networking $(3,4,5)$. These steps ensure effective collaboration.

E-pedagogy has to make a special focus on communication, socialization and collaboration in the online learning environment.

\section{E-pedagogy - Pedagogy for Formal Online Higher Education}

Online educators need a comprehensive, research-based, and consistent theory of online education offering a holistic and insightful view of the field without which there will be no quality teaching and learning. Such a theory will provide a conceptual base of online education, along with setting the expectations for pedagogically sound and thus effective designing, planning and implementing both teaching and learning; help understand online students and their learning process; provide methodological directions, strategies, and advice; prepare instructors for effective online practices, and help maintain their professionalism.

As the term 'e-learning' has been established to denote online learning, it would be logical to call the emerging pedagogy of online education 'e-pedagogy'. We argue that pedagogy, being a generic term for broad pedagogic science, integrates many parts, such as teaching, learning, personal development, instructional methods, etc. Therefore, in the author's opinion, it would be incorrect to call e-pedagogy the pedagogy of e-learning, as was suggested in the article under such title (Mehanna, 2004) - the latter is only a part of the broad, all-embracing e-pedagogy.

Like traditional pedagogy, e-pedagogy has to describe current educational theories and methodologies; identify the purpose of education and basic principles of online education built on research and understanding of the traditional and web-based education together with current trends and future developments; consider the processes of learner personal, cognitive and social development.

E-pedagogy has four major educational theories as its foundation:

- Behaviorist learning theory (B. Skinner)

- Cognitivist learning theory (J. Piaget)

- Constructivist learning theory (Schell \& Janicki, 2012)

- Collaborative learning theory (Harasim 2012)

E-pedagogy is a comprehensive science which integrates all issues related to the online education, starting with the theoretical foundations, and embracing higher education institutions, pedagogic systems, personal and professional development, principles of teaching and learning, instructional approaches and methods; knowledge construction in the online environment; student and instructor's characteristics, roles, functions, dispositions and preparedness for the learning; educational technologies, course design and process planning. Projection of pedagogy on the learning process as a system of applications forms methodology of teaching and learning.

Based on the analysis of various pedagogies, the author suggests a model of e-pedagogy which includes the following parts:

1. Foundations of Online Pedagogy

1.1. Education as a humanistic and professional value

1.2. Goals and functions of education

1.3. Education as a social and pedagogic process

1.4. Pedagogy as a science

1.5. Educational systems

1.6. Educational psychology

1.7. Major educational theories

- Behaviorist learning theory

- Cognitivist learning theory

- Constructivist learning theory

- Collaborative learning theory

1.8. Specifics of online pedagogy and its place in general pedagogy

1.9. Links between pedagogy and other sciences

1.10. Current trends and future developments in education 
2. Online higher education
2.1. Goals
2.2. Types
2.3. Structures
2.4. Formats

3. Human development as a pedagogic problem

3.1. Formation of an individual as a person, society member and a specialist as a pedagogic problem

3.2. Learning as a developmental process: cognitive, emotional, social, moral and professional development

3.3. Students' characteristics, abilities and learning styles (adult vs. traditional student; students in online vs. brick-andmortar environments)

3.4. Student dispositions

3.5. Motivation

3.6. Socialization in education

3.7. Self-development in the process of learning. Learner autonomy and self-efficacy

4. Principles of teaching and learning

4.1. Contemporary pedagogic approaches

4.2. Content of education

4.3. Knowledge construction

4.4. Collaboration and cooperation in teaching and learning

4.5. Educational and professional standards and expectations

4.6. Application of new knowledge and skills in real life and job situations

5. Methods and tools

5.1. Instructional approaches

5.2. Methods of education

5.3. Content presentation

5.4. Inquiry and problem solving

5.5. Interaction and socialization in learning

5.6. Teaching and learning tools

6. Educational technologies

6.1. Technical and educational characteristics

6.2. Online learning technologies. Learning Management Systems (LMS)

6.3. Social networking tools

6.4. Mobile learning tools

6.5. Technology-based teaching and learning

7. Methodology of teaching and learning
7.1. Instructor and student in the educational process

7.2. The logics and structure of the process

7.3. Types of learning

7.4. Learning strategies and techniques

7.5. Communicative and networking tactics

7.6. Quality control in education: feedback, reflection, assessment and evaluation

8. Online instructor

8.1. Professional qualifications

8.2. Professional culture and dispositions

8.3. Preparation and continuous professional development

8.4. Pedagogic activities in an online environment

8.5. Instructor's roles and functions

8.6. Teaching style and interactions with students

9. Designing online education

9.1. Course design

9.2. Course structure

9.3. Instructor activities

9.4. Student activities

9.5. Course materials: modalities and formats

9.6. Course tools and navigation

9.7. Student assessment and support

10.Planning and time management in teaching and learning

10.1. Course and lesson planning

10.2. Time management

This model of e-pedagogy is all-inclusive and may serve as a backbone for a comprehensive theory of online education. What theoreticians, as well as practitioners of online education have to remember is:

1. E-pedagogy is balanced between classical education theory, psychology, sociology and technology.

2. It is never static, but constantly evolving and transforming along with the new technologies and social processes, which requires its continuous modification.

3. The proof of its effectiveness is the students' learning outcomes. 


\section{Conclusion}

E-pedagogy is the foundation of effective online education. In view of the growing demand for the online university classes, its development is urgent. It requires close collaboration within the online educators' community. A special conference which would assemble theoreticians and practitioners interested in this largescale work might well serve this need. Actually, this pedagogy is intended primarily for the online educators, while students, especially those who undertake self-education using MOOC's or free online resources, or engage in informal web-based educational endeavors, need a special manual, e.g., Online Learning for Fools, which should also be written.

\section{References}

[1] T. ANDERSON, Toward a Theory of Online Learning, 2004. http://cde.athabascau.ca/online_bo ok/ch2.html

[2] T. ANDERSON, J. DRON, Three generations of distance education pedagogy. International Review of Research in Open and Distance Learning, 12(3), March 2011.

[3] Association of Learning Technologies. Technology in learning, 2010.

http://repository.alt.ac.uk/839

[4] J. Bocchi, J. EASTMAn, C. SWIFT, Retaining the online learner: Profile of students in an online MBA program and implications for teaching them. Journal of Education for Business, 79(4), pp. 245-53, 2004.

[5] J. BRUNER, Folk Pedagogies, in Foundations of New Reform. In J. LEACH, B. MOON (Eds.), Learners and Pedagogy, London: Paul Chapman, 1999.

[6] M. CASEY, Has technology ruined handwriting? CNN, $07 / 26 / 2013$

http://www.cnn.com/2013/07/26/tech/web/ impact-technology-handwriting/

[7] E. ClARK, Communication - The Achilles Heel of Online Learning, 2013. http://www. linkedin. com/today/post/article/20140604160445-6 0151704-communication-the-achilles-heel -of-online-learning

[8] College Preparedness Lacking, Forcing Students into Developmental Coursework, Prompting Some to Drop Out. Huffington Post, 2012. http:// www . huffingtonpost. com/2012/06/18/stude nts-lacking-college-n_1606201.html
[9] L. HARASIM, Learning theory and online technologies. New York: Routledge, 2012.

[10] C. Haythornthwaite, R. AndREws, E-learning Theory and Practice. London: Sage, 2011.

[11] A. Herrington, A. Bunker, Quality teaching online: Putting pedagogy first. Proceedings of HERDSA, 2002. http://gre-guns2.gre.ac .uk /ET/ELD/KNTI/etutres.NSF/ba86bb22bb63c 1f980256a520002e72e/0074e391cc34d4d6802 56fe7007aac5a/\$FILE/HerringtonA.pdf

[12] Higher Education: Open for Business. Ed. by C. Gilde. Lanham: Lexington books, 2007.

[13] R. HiLl, P. SERDYUKOV, Setting the example: Role modeling in an online class. Proceedings of Society for Information Technology and Society for Information Technology and Teacher Education $21^{\text {st }}$ International Conference (SITE), March 29 - April 2, San Diego, 2010.

[14] C. HMElo-SILVER, Facilitating Collaborative Knowledge Construction. Proceedings of the 36th Hawaii International Conference on System Sciences (HICSS'03), 2003.

[15] H. HoLEC, Autonomy and foreign language learning. Oxford: Pergamon, 1981.

[16] D. Knowlton, Promoting Durable Knowledge Construction through Online Discussion. 6th Annual Instructional Technology Conference "Developing a Participatory Learning Culture”, Middle Tennessee State University, April 2001. http://frank. mtsu.edu/ itconf/proceed0 1/11.html

[17] J. LAVE, E. WENGER, Situated learning: legitimate peripheral participation. Cambridge: Cambridge University Press, 1991.

[18] Z. LIU, Z. YANG, Factors Influencing DistanceEducation Graduate Students' Use of Information Sources: A User Study. The Journal of Academic Librarianship, 30(1), pp. 24-35, 2004. http://www.sciencedirect.com/science/ar ticle/pii/S0099133303001381

[19] Y. LoU, P. ABRAMI, S. D’Apollonia, Small Group and Individual Learning with Technology: A MetaAnalysis. Review of Educational Research, 71(3), pp. 449-521, Autumn, 2001.

[20] H. Maurer, R. Mehmood, P. Korica-Pehserl, How Dangerous is the Web for Creative Work? Journal of Computing and Information Technology, 21(2), pp. 59-69, 2013.

[21] W. Mehanna, E-pedagogy: the pedagogies of e-learning. ALT-J, Research in Learning Technology, 12(3), September 2004. http://files. eric.ed.gov/fulltext/EJ821507.pdf

[22] Microsoft Encarta College Dictionary: The First Dictionary for the Internet Age. New York: Bloomsbury Publishing Plc, 2001. 
[23] G. Miller, M. Benke, B. Chaloux, L. Ragan, R. Schroeder, W. SMutz, K. Swan, Leading the e-Learning Transformation in Higher Education: Meeting the Challenges of Technology and Distance Education. Sterling, VA: Stylus Publishing, 2014.

[24] M. MoOre, Three types of interaction. The American Journal of Distance Education, 3(2), pp. 1-5, 2001.

[25] M. Moore, G. KeARSLey, Distance Education: A Systems View of Online Learning. Cengage Learning, 2011.

[26] D. MupingA, R. NORA, D. YAW, The learning styles, expectations, and needs of online students. College Teaching, 54(1), pp. 185-189, 2006.

[27] M. NicKOLS, Articulating E-pedagogy for Education. Open Learning for an Open World: Reflections on Open and Distance Learning and Teaching at the Open Polytechnic of New Zealand. (Ed. by J. BARRETT), pp. 321-336, 2011. http://repository.openpolytechnic.ac.nz /bitstream/handle/11072/1381/Seelig_et\% 20al_2011\%20-\%20Book\%20-\%200pen_Learnin g_for_an_Open_World.pdf?sequence=

[28] A. PALINCSAR, Social Constructivist Perspectives on Teaching and Learning. Annual Review of Psychology, 49, pp. 345-75, 1998.

[29] S. PAPPERT, A Critique of technocentrism in thinking about the school of the future, 1990. http: //www . papert.org/articles/ACritiqu eofTechnocentrism.html

[30] N. Postman, Technopoly: The Surrender of Culture to Technology. New York: Vintage Books, 1993.

[31] E. Reichle, P. CARpenter, M. Just, The Neural Bases of Strategy and Skill in Sentence-Picture Verification. Cognitive Psychology, 40(4), pp. 261-295, 2000. http://repository.alt.ac.uk/839/2/ ALT_TEL_evidence_document_for_BIS_low-re s.pdf

[32] Sampson, D., Isaias, P., Ifenthaler, D., SpeCTOR, M.\}, UBIQUITOUS AND MOBILE LEARNING IN THE Digital AGE. NEW YoRK: SPRINGER, 2013.

[33] M. Scardamalia \& C. Bereiter, Knowledge BUILDING. IN Encyclopedia of Education, SECOND EDITION. NEW YORK: MACMILLAN REFERENCE, 2002. http://ikit.org/fulltext/in pressKB.pdf

[34] G. SCHELl \& T. JANICKI, ONLINE COURSE PEDAGOGY AND THE CONSTRUCTIVIST LEARNING MODEL. J. of Southern Association for Information Systems, 1(1), PP. 26-36, 2012.

[35] P. Serdiukov, Models of Distance Higher EdUCATION: FUlly AUTOMATED OR PARTIALly HUMAN? Educational Technology Review. International Journal on Educational Technology Issues \& Applications, 9(1), PP. 16-28, 2001.
[36] P. SERDYUKOV \& R. Hill, E-LEARNING: WHAT WORKS, WHAT DOESN'T, WHAT NOW? Proceedings of E-Learn World Conference on E-Learning in Corporate, Government, Healthcare, \& Higher Education, LAS VEGAS, NOVEMBER 17-21, 2008.

[37] P. Serdyukov \& N. Serdyukova, Adult learnERS IN AN ONLINE COLLEGE CLASS: COMBINING EFFICIENCY AND CONVENIENCE OF E-LEARNING. Education for the $21^{\text {st }}$ century: Impact of ICT and digital resources. NY: SPRINGER, PP. 205-214, 2006.

[38] P. Serdyukov \& N. Serdyukova, Effective COMMUNICATION IN ONLINE LEARNING. Proceedings of the $9^{\text {th }}$ WCCE IFIP World Conference on Computers in Education. Bento Goncalves, BRAZIL. July 27-30, 2009. http: //www.wcce2009.org/proceedings/pap ers/WCCE2009_pap124.pdf

[39] N. SERdyukova, P. SERdyukov, Student AutonOMY IN ONLINE LEARNING. Proceedings of CSEDU 2013 5th International Conference on Computer Supported Education. AACHEN, GERMANY, 2013. http://www.scitepress.org/DigitalLibrar y/Link . aspx?doi=10.5220/0004353102290233

[40] G. Siemens, Connectivism: A Learning TheORY FOR THE DIGITAL AGE. International Journal of Instructional Technology and Distance Learning, 2(1), 2005.

[41] M. Simonson, S. Smaldino, M. Albright, S. ZVACEK, TEACHING AND LEARNING AT A DISTANCE: FOUNDATIONS OF DISTANCE EDUCATION. Boston: Pearson Education, Inc., 2012.

[42] D. SousA, How the Brain Learns Mathematics. Thousand Oaks, CA: Korwin, 2014.

[43] M. SPITZER, Digitale Demenz. Wie wir uns und unsere Kinder um den Verstand bringen. Roemer Verlag, 2012.

[44] The Trouble with Online College, 02/19/2013. New York Times.

[45] L. Vygotsky, Thought and language. Cambridge, Massachusetts: M.I.T. Press, 1962.

[46] EdS. H. F. O’NeIL, R. S. PEREZ, Web-Based Learning: Theory, Research, and Practice. New York: Routledge, 2013.

[47] G. ZIPF, Human Behavior and the Principle of Least Effort, Cambridge, Massachusetts: AddisonWesley, 1949.

Received: October, 2014 Accepted: October, 2014

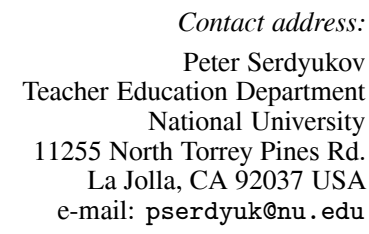


PETER SERDYUKOV, Doctor of Pedagogic Sciences in Educational Technology Applications (Kiev State Linguistic University 1997), PhD in Structural and Mathematics Linguistics (Kiev State Pedagogic Institute of Foreign Language 1979).

Chair, Department of Educational Technology and Informatics, Kiev State Linguistic University, Ukraine (1982-1998).

Professor, Teacher Education Department, School of Education, National University, La Jolla, CA USA (2001-present).

Author of 120 books, chapters, articles and conference presentations in educational technology, online learning, instructional methodology, teacher preparation and adult learning. 